\title{
Morphology of the first instar larva of obligatory traumatic myiasis agents (Diptera: Calliphoridae, Sarcophagidae)
}

\author{
K. Szpila • M. J. R. Hall • A. H. Wardhana • T. Pape
}

Received: 13 December 2013 / Accepted: 2 February 2014 / Published online: 20 February 2014

(C) The Author(s) 2014. This article is published with open access at Springerlink.com

\begin{abstract}
There are only three fly species that are obligate agents of traumatic myiasis of humans and livestock: a single species of flesh fly, Wohlfahrtia magnifica (Sarcophagidae), and two species of blow flies, Chrysomya bezziana and Cochliomyia hominivorax (Calliphoridae). The morphology of their first instar larvae is thoroughly and consistently documented here with light microscopy photographs and scanning electron microscopy micrographs. The following morphological structures are documented: pseudocephalon, antennal complex, maxillary palpus, oral ridges, thoracic and abdominal spinulation, spiracular field, posterior spiracles and cephaloskeleton. New diagnostic features drawn from the cephaloskeleton and the spinulation of abdominal segments, including the anal pad, are discovered and extensively described. Earlier descriptions in the literature are revisited, and major discrepancies between these and the results of the current study are discussed. The present results allow clarification, correction and, especially, complementation of
\end{abstract}

\section{K. Szpila $(\square)$}

Chair of Ecology and Biogeography, Faculty of Biology and

Environmental Protection, Nicolaus Copernicus University,

Lwowska 1, Toruń 87-100, Poland

e-mail: szpila@umk.pl

\section{J. R. Hall}

Department of Life Sciences, Natural History Museum, Cromwell

Road, London SW7 5BD, UK

e-mail: M.Hall@nhm.ac.uk

\section{A. H. Wardhana}

Department of Parasitology, Indonesian Research Centre for

Veterinary Science, JL. Martadinata 30, Bogor, West Java, Indonesia

e-mail: Wardhana24id@yahoo.com

\section{T. Pape}

Natural History Museum of Denmark, University of Copenhagen, Universitetsparken 15, Copenhagen 2100, Denmark

e-mail: TPape@snm.ku.dk information provided by earlier authors. The relatively distant taxonomic position of all three species is evidence that obligatory myiasis has arisen independently, and the extensively similar morphology in the first instar larvae of Chrysomya bezziana, Cochliomyia hominivorax and W. magnifica in comparison to necrophagous species, especially the enhancement of the anterior part of the cephaloskeleton and the segmental spinulation, is therefore best interpreted as homoplasic adaptations to a life strategy as obligate vertebrate parasites. An identification key for first instar larvae of all obligatory traumatic myiasis agents of mammals is provided.

Keywords Obligatory traumatic myiasis agents · Chrysomya bezziana Cochliomyia hominivorax . Wohlfahrtia magnifica . First instar larva $\cdot$ Morphology $\cdot$ Identification $\cdot$ SEM

\section{Introduction}

Traumatic myiasis of domestic animals and humans is a serious parasitic condition causing high economic losses around the world in addition to the suffering of those afflicted (Hall and Wall 1995). This kind of myiasis can involve several species of blowflies and fleshflies, but among these, only three are considered to be obligatory traumatic myiasis agents (abbreviated below as OTMA), and care needs to be taken in their identification (Hall 2008). These three species, Chrysomya bezziana Villeneuve, 1914, Cochliomyia hominivorax (Coquerel, 1858) and Wohlfahrtia magnifica (Schiner, 1862) are obligatory parasites, which under natural conditions complete their larval development only in the tissues of living vertebrates (Spradbery 1994; Sotiraki et al. 2010).

Until the second half of the twentieth century, the geographical distribution of these three OTMAs did not overlap, with the presence of Chrysomya bezziana confined to the 
Oriental Region and sub-Saharan Africa, Cochliomyia hominivorax in the warmer parts of the New World and W. magnifica in southern areas of the Palaearctic Region (Spradbery 1994; Hall and Farkas 2000). This situation was changed by the human-assisted introduction of Cochliomyia hominivorax to North Africa and the expansion of Chrysomya bezziana into the southern parts of the Palaearctic Region (Spradbery 1994; Lindquist et al. 1992). Cochliomyia hominivorax was successfully eradicated from the Old World (Lindquist et al. 1992), but Chrysomya bezziana seems to be well established in at least some Middle East countries, e.g. Iran and Oman (Hall et al. 2009). The entire Mediterranean Region is an area of potential sympatry of all OTMA species (Sutherst et al. 1989).

According to their considerable economic and medical importance, OTMA species have been the subject of intense research into many aspects of their biology and morphology (e.g. Laake et al. 1936; Kitching 1976; Ruiz-Martinez et al. 1989, 1990). However, most contributions to larval morphology have been concentrated on third instar larvae, L3 (e.g. Knipling 1939; Zumpt 1965; Erzinçlioğlu 1987; Spradbery 2002; Hall 2008; Florez and Wolff 2009). Morphology of the first instar larva, L1, was omitted or treated superficially because it has a relatively short developmental period and, therefore, is rarely encountered during the collection of specimens from infested wounds (Hall 2008).

Descriptions and illustrations of the L1 of Chrysomya bezziana are available in the publications of Zumpt (1965), Kitching (1976), Gan (1980) and Spradbery (2002). None of these studies contains an elaborate documentation of larval morphology. Zumpt (1965) provided only a brief description of the larval habitus, and both Kitching (1976) and Spradbery (2002) gave somewhat superficial descriptions supported by a few scanning electron micrographs. Gan (1980) presented an excellent drawing of the cephaloskeleton accompanied by a very short description of this structure. The morphology of the L1 of Cochliomyia hominivorax has been better documented than that of Chrysomya bezziana, mostly thanks to Laake et al. (1936). This landmark paper was taken further by the contribution of Leite and Guevara (1993), where several SEM micrographs are used for illustrating a number of morphological characters, although the associated description is rather superficial. An important contribution was made by Lopes (1983), who presented a figure of the anterior part of the cephaloskeleton of the L1 of Cochliomyia hominivorax, with the addition of a few comments concerning cephaloskeleton diversity in Calliphoridae and Sarcophagidae. Details of the morphology of the L1 of $W$. magnifica were presented by Valentyuk (1971) and Schumann et al. (1976). Lehrer and Fromunda (1986) provided a detailed and fully illustrated description, but this was largely restricted to the cephaloskeleton. Line drawings, detailed descriptions and SEM micrographs of larvae of $W$. magnifica were included in two papers of Ruiz-Martinez et al. (1989, 1990). However, for the L1, the SEM documentation was restricted to the exposed parts of the mouthhooks and labrum, as well as the spines of the anterior thoracic segments (Ruiz-Martinez et al. 1990), and their interpretations and terminology are partly conflicting with what is presented here.

Recent studies of larval morphology of higher Diptera have introduced high standards of documentation (e.g. Grzywacz et al. 2012; Klong-klaew et al. 2012; Sanit et al. 2012; Semelbauer and Kozánek 2012; Szpila et al. 2013; Velasquez et al. 2013), and it is appropriate and timely to revise the available morphological documentation of such medically and economically important species as the OTMAs to a similar high quality. Until now, no identification key to the L1 of all three OTMA species has been published.

The objectives of the present paper were (1) to revise existing data concerning the L1 morphology of the known OTMAs, (2) to expand this knowledge by providing new data and (3) to prepare an easily applied identification key to the L1 of all OTMAs.

\section{Material and methods}

Larvae of Chrysomya bezziana and Cochliomyia hominivorax were obtained from laboratory colonies maintained at the Indonesian Research Centre for Veterinary Science, Bogor, Indonesia, and the Mexican-American Commission for the Eradication of Screwworm (COMEXA), Chiapa de Corzo, Mexico, respectively. Larvae of W. magnifica were obtained from gravid females collected from rural surveys around Budapest, Hungary (Hall et al. 2009).

For all species, live larvae were killed by immersion for $30 \mathrm{~s}$ in hot water (about $80-95{ }^{\circ} \mathrm{C}$ ) to extend the pseudocephalon and avoid subsequent deformation when stored in $70 \%$ ethanol (Adams and Hall 2003).

Ten L1 of each species were slide-mounted in Hoyer's medium (Cielecka et al. 2009) for light microscopy. A Nikon 8400 digital camera mounted on a Nikon Eclipse E200 microscope (Nikon Corporation, Tokyo, Japan) was used for photomicrography. Another ten L1 of each species were prepared for SEM by dehydration through 80, 90 and $99.5 \%$ ethanol, critical point dried in $\mathrm{CO}_{2}$ and sputter-coated with platinum. SEM images were taken with a JEOL JSM-6335F scanning electron microscope (JEOL Ltd., Tokyo, Japan).

Morphological terminology follows Courtney et al. (2000) and Szpila and Villet (2011). In particular, for the sensory cluster in the central part of the maxillary palpus, Szpila et al. (2008) classified the most prominent six sensilla as three sensilla coeloconica and three sensilla basiconica. This may be too generalised as sb3 deviates by being a composite structure of a small sensilla associated with an ear-like fold of the integument. We maintain the terminology of Szpila 
et al. (2008) acknowledging that more elaborate studies (e.g. histological, developmental genetic) may bring evidence that leads to an improved terminology.

\section{Results}

Redescriptions of the first instar larva of Chrysomya bezziana, Cochliomyia hominivorax and Wohlfahrtia magnifica

The L1 of all OTMAs possess the general habitus characteristic for most Calyptratae, being divided into a bilobed pseudocephalon (termed pc), three thoracic segments ( $\mathrm{t} 1-\mathrm{t} 3$ ), seven abdominal segments (a1-a7) and an anal division (ad), which carries the posterior spiracles (Fig. 7a-c). Each thoracic segment has a pair of Keilin's organs located ventrally (Figs. $2 \mathrm{~g}$ and $4 \mathrm{f}$ ). Laterally on t1, close to the posterior edge of the segment, is located the simple aperture of the anterior spiracle, usually overlooked in descriptions of L1 (Fig. 4a). Each of a1-a7 and ad has a transverse crevice on the ventral surface and lateral creeping welts (Fig. 3a). Specific morphological details are described separately for each species.

Chrysomya bezziana Villeneuve, 1914 (Figs. 1a-g; 6a, b; and $7 \mathrm{a})$

Pseudocephalon: Antennal complex with slightly elongated dome, height of basal ring less than length of antennal dome (Fig. 1c); maxillary palpus with three sensilla coeloconica and three sensilla basiconica (sc1-sc3, sb1-sb3) clustered in the central part, sb3 not distinct (Fig. 1d), one or two additional, small sensilla are situated close to sb1, two additional sensilla coeloconica (ns1, ns2) of typical appearance are arranged laterodorsally on the surface of the maxillary palpus, central cluster of sensilla surrounded by several crescent-shaped protuberances; labial lobe narrow and elongated, almost parallel-sided (Fig. 1b); ventral organ small, situated lateral to the functional mouth opening and level with the adjacent integument (Fig. 1b, e); oral ridges terminate medio-laterally on pseudocephalon (Fig. 1a). Cephaloskeleton: mouthhooks large, strongly sclerotised and equally broad for the entire length (Fig. 6a), apical part with numerous (10-13), long, strongly sclerotised, pointed teeth arranged in a large cluster and with tips orientated ventrally, three to fourth teeth of each mouthhook larger than others (Figs. 1a, b and 6a, b); labrum long, with well differentiated narrower apical part, broad basal part of labrum at most $1.5 \times$ as long as narrow apical part (Fig. 6a); intermediate sclerite Hshaped in ventral view (Fig. 6b); parastomal bars broad and straight in lateral view (Fig. 6a, b); vertical plate very wide, about three times wider than greatest width of dorsal cornua; dorsal cornua slightly longer than ventral cornua, ventral cornua at widest point $1.5 \times$ as wide as dorsal cornua (Fig. 6a); dorsal bridge present (Fig. 6b). Thoracic segments: anterior spinose band on $\mathrm{t} 1$ broad, with spines arranged in 7-8 rows dorsally and 12-14 rows ventrally (Figs. 1a and 6a), spines large and slightly flattened, with broad triangular base and slender, curved, hook-like tip, size of spines decreasing gradually towards the posterior end of the body (Fig. 1a); anterior spinose bands of $\mathrm{t} 2 \mathrm{-t} 3$ with homogeneous, strongly sclerotised, slightly flattened spines, tip of spines curved. Abdominal segments: anterior spinose bands complete on a1-a5, narrowly interrupted dorsally on a6, on a7 the band is incomplete being interrupted dorsally and laterally (Fig. 7a), spines on ventro-lateral surfaces of each segment larger than other spines, each anterior spinose band ventrally with a transverse lenticular gap without spines (Fig. 1f); posterior spinose band absent on a1, on a2-a4 band present as a single row of ventral spines with few additional spines ventrolaterally, on a5 spines present as a single ventral row with an additional small group of spines laterally, a6 with posterior band interrupted dorsally and laterally, band on a7 complete with a single row of spines laterally and with 2-3 rows ventrally and dorsally (Fig. 7a). Anal division: Anal pads rounded, slightly protruding (Fig. 1g), anal tuft with several spines dorsally, readily apparent in light microscope; hair-like spines around spiracular field entirely absent (Fig. 1g), several conical spines present along ventral edge of spiracular field; posterior spiracles each with four peristigmatic tufts of similar size, tufts broad with distal margin shallowly serrated to form four to seven irregular branches; anterior spinose band developed only ventrally and ventrolaterally (Fig. 1g); p1, p3 and p5 developed as cones with a long sensillum on the extremity resembling a large sensillum coeloconica, $\mathrm{p} 7$ with sensillum on small protuberance, $\mathrm{p} 2, \mathrm{p} 4$ and $\mathrm{p} 6$ developed as sensilla situated level with adjacent integument (Fig. 1g).

\section{Cochliomyia hominivorax (Coquerel, 1858) (Figs. 2a-h;} $3 a-d ; 6 c, d$; and $7 b$

Pseudocephalon: Antennal complex with slightly elongated dome, height of basal ring less than length of antennal dome (Fig. 1c); maxillary palpus with three sensilla coeloconica and three sensilla basiconica (sb1-sb3, sc1-sc3) clustered in the central part, sb3 not distinct (Fig. 2d), one or two additional small sensilla are situated close to sb1, two additional typical sensilla coeloconica (ns1-ns2) arranged laterodorsally on the surface of the maxillary palpus; labial lobe triangular (Fig. 2e); ventral organ small, situated lateral to the functional mouth opening and level with the adjacent integument (Fig. 2e, f); oral ridges terminate medio-laterally on pseudocephalon (Fig. 2a, b). Cephaloskeleton: mouthhooks strongly sclerotised in anterior and mid parts, mid part of mouthhooks bar-like, slightly curved and equally broad for the entire length, apical part with six to 

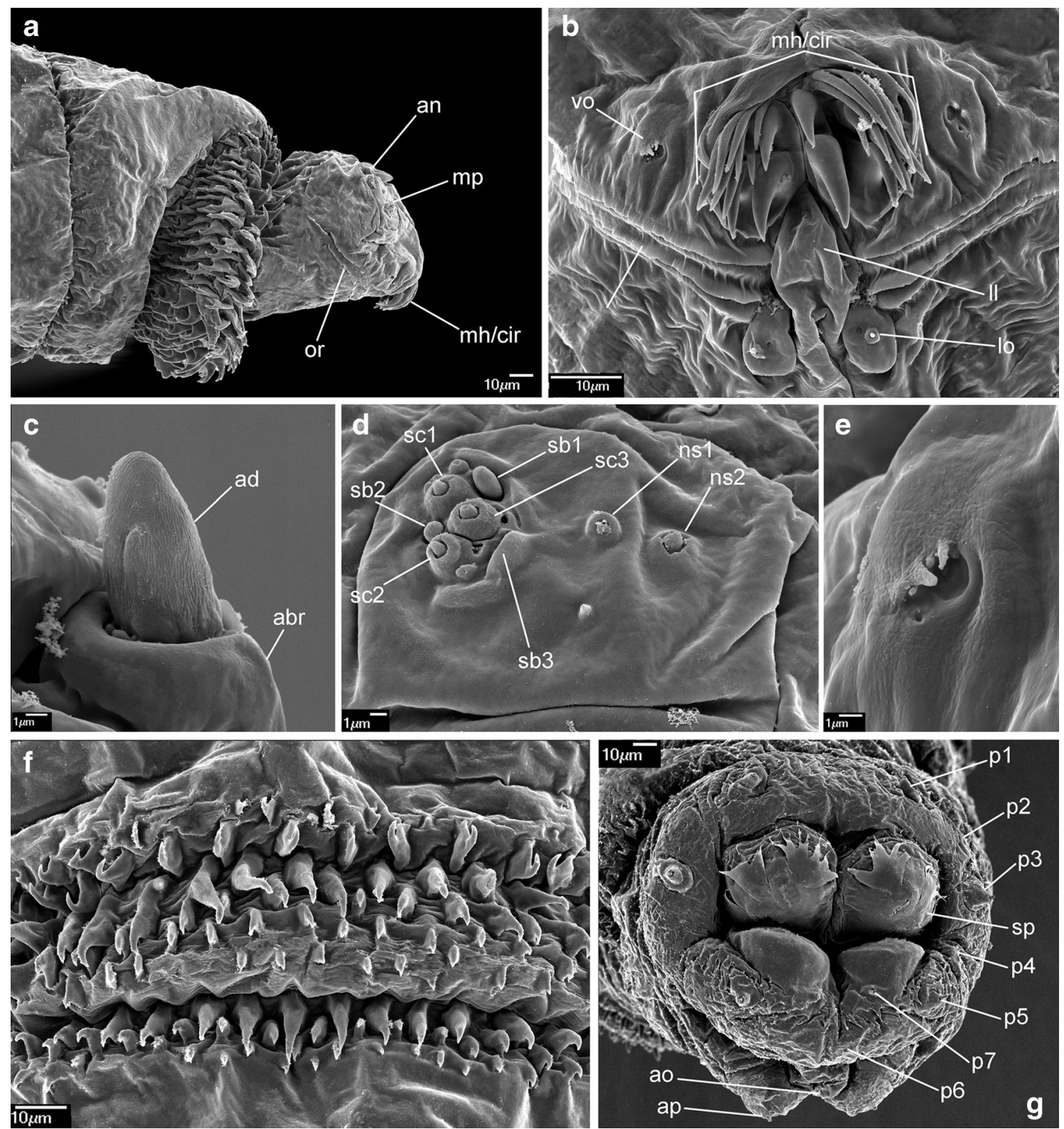

Fig. 1 First instar of Chrysomya bezziana. a Anterior end of body, lateral view. b Functional mouth opening. c Antennal complex. d Maxillary palpus. e Ventral organ. f Third abdominal segment, ventral view, anterior spines. g Anal division, posterior view. Abbreviations: $a b r$ antennal basal ring, ad antennal dome, an antennal complex, ao anal opening, ap anal

eight long, strongly sclerotised, pointed teeth arranged in a large cluster and with tips orientated ventrally, teeth with only slightly differentiated size, basal part of mouthhook slightly sclerotised with visible lateral arm (Figs. 2b, e and 6c, d); labrum long, with well differentiated narrower apical part, broad basal part of labrum $3 \times$ longer than short, narrow apical part (Fig. 6c); intermediate sclerite $\mathrm{H}$-shaped in ventral view (Fig. 6d); parastomal bars broad and straight in lateral view; vertical plate very wide, about $3 \times$ as wide as widest part of dorsal cornua; dorsal cornua slightly longer than ventral cornua, ventral cornua with similar width to the dorsal cornua; dorsal bridge absent (Fig. 6d). pad, cir cirri, $m h$ mouthhooks, $m p$ maxillary palpus, $l l$ labial lobe, lo labial organ, $n s 1$ first additional sensillum coeloconicum, $n s 2$ second additional sensillum coeloconicum, or oral ridges, $p 1-p 7$ papillae 1-7 sb1-sb3 sensilla basiconica, $s c 1-s c 3$ sensilla coeloconica, $s p$ posterior spiracle, vo ventral organ

Thoracic segments: anterior spinose band on t1 broad, with spines arranged in 6-7 rows dorsally and 10-12 rows ventrally, spines large and elongated, size of spines decreasing gradually towards the posterior end of body, anterior-most spines of each segment very long and almost straight with only apical part curved (Figs. 2a, b and 6c); anterior spinose bands of $\mathrm{t} 2$ and $\mathrm{t} 3$ with homogeneous, strongly sclerotised, elongated spines. Abdominal segments: anterior spinose bands complete on a1a5, interrupted dorsally by narrow break on a6, on a7 band incomplete being interrupted dorsally and laterally (Fig. 7b), spines on ventro-lateral surfaces of each segment larger than 

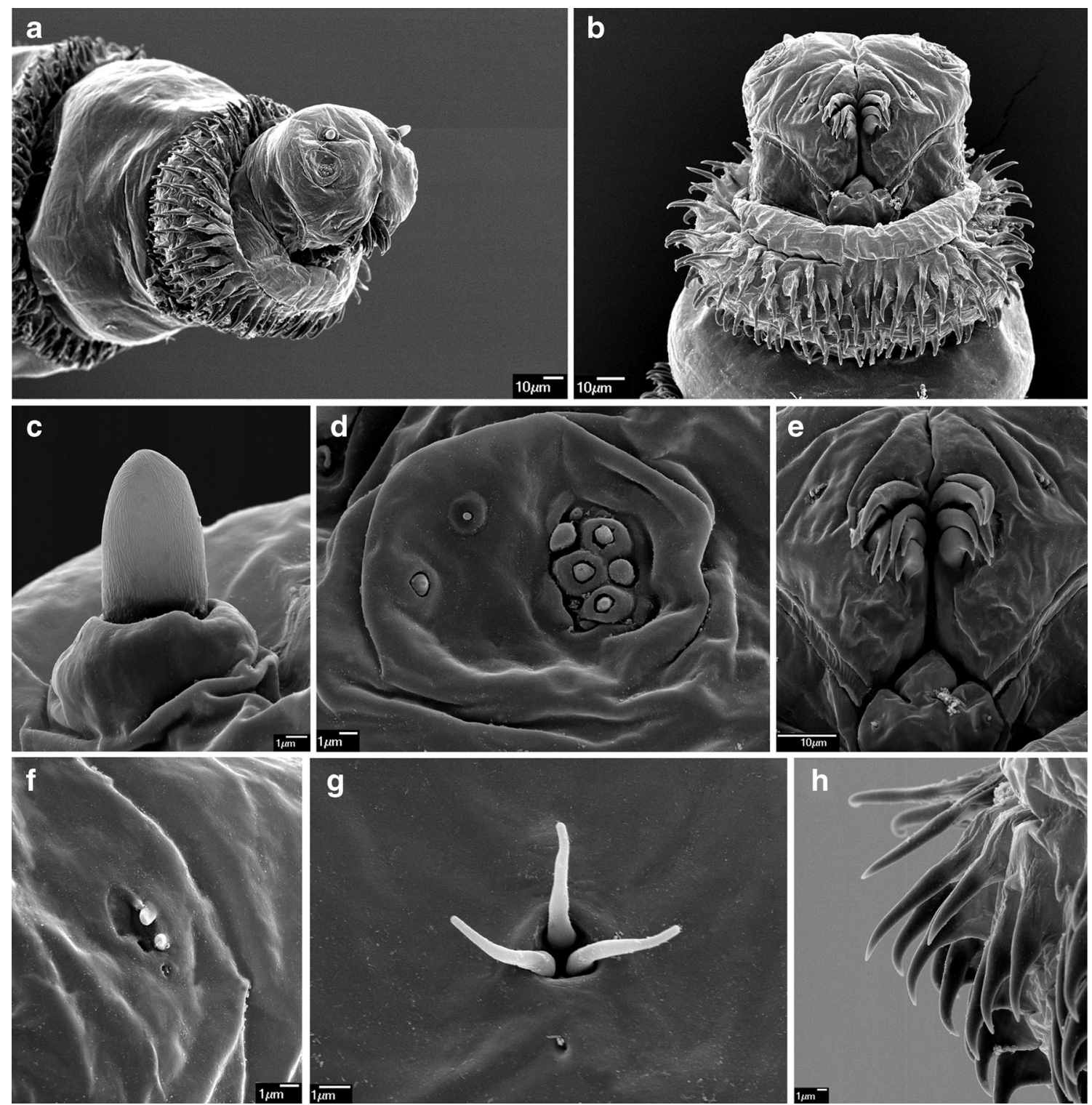

Fig. 2 First instar of Cochliomyia hominivorax. a Anterior end of body, antero-lateral view. b Anterior end of body, ventral view. c Antennal complex. d Maxillary palpus. e Functional mouth opening. f Ventral organ. g Keilin's organ. h First thoracic segment, spines

other spines, each anterior spinose band ventrally with a transverse lenticular gap without spines (Fig. 3a); all posterior spinose bands incomplete, spines present only as single row of spines on ventral surface with few additional spines on ventrolateral surfaces (Fig. 7b); lateral creeping welts with strong spines directed posteriorly only the most posterior lateral creeping welt without spines. Anal division: Anal pads rounded, small and slightly protruding (Fig. 3c), anal tuft with few spines dorsally, readily apparent in light microscope; circle of hair-like spines around spiracular field entirely absent (Fig. 3d), several small conical spines present along ventral edge of spiracular field; posterior spiracles each with four peristigmatic tufts of differentiated size (Fig. 3d), dorso-lateral tuft narrower than others, other tufts broad and serrated to form three to six broad branches; anterior spinose band developed only ventrally and ventrolaterally (Fig. 7b); p1, p3 and p5 developed as small cones with a short sensillum on the extremity resembling a large sensillum coeloconica, $\mathrm{p} 7$ with sensillum on small protuberance, p2, p4 and p6 developed as sensilla situated level with adjacent integument.

Wohlfahrtia magnifica (Schiner, 1862) (Figs. 4a-h; 5a-e; 6e, f; and 7c)

Pseudocephalon: Antennal complex with slightly conical dome, height of basal ring greater than length of antennal dome (Fig. 4c); maxillary palpus encircled by several cuticular folds, central cluster of sensilla with three sensilla coeloconica and three sensilla basiconica (sb1-sb3, sc1-sc3) (Fig. 4d), few other 
Fig. 3 First instar of Cochliomyia hominivorax. a Abdominal segments 1-3, ventral view. b Abdominal segment 2, spines. c Anal division, ventral view. d Anal division, posterior spiracles. Abbreviations: $a 1-a 3$ abdominal segments $1-3$, ao anal opening, ap anal pad, $a s b$ anterior spinose band, at anal tuft, $l \mathrm{cw}$ lateral creeping welt, $p s b$ posterior spinose band, $s t$ peristigmatic tufts
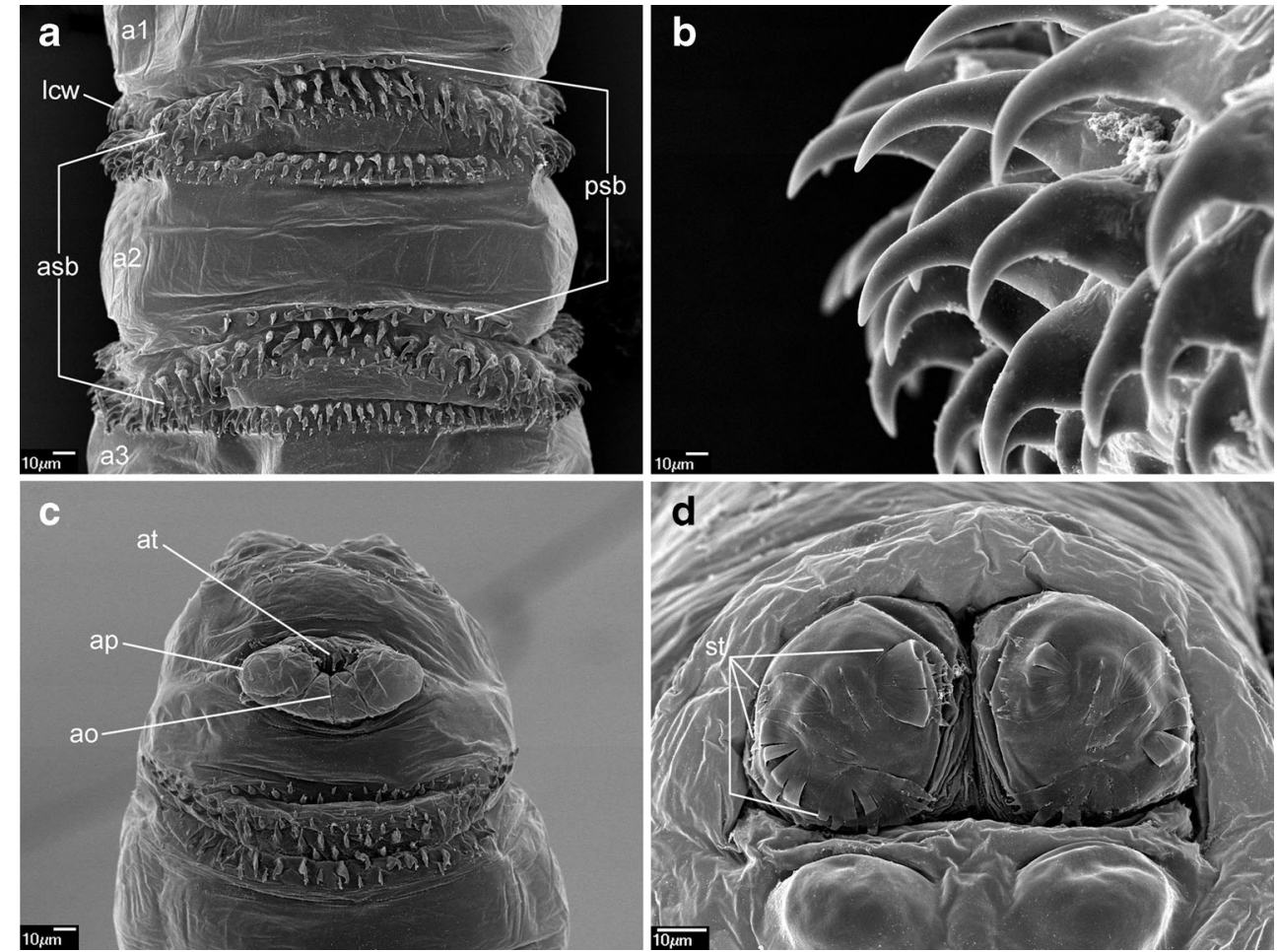

small sensilla are situated close to sb1, two additional sensilla coeloconica (ns1-ns2) of typical appearance arranged laterodorsally on the surface of the maxillary palpus (Fig. 4d); ventral organ small, situated lateral to the functional mouth opening and level with the adjacent integument (Fig. 4b, e); oral ridges terminate medio-laterally on pseudocephalon (Fig. 4a). Cephaloskeleton: mouthhooks large and strongly sclerotised, anterior part of each mouthhook strongly curved downward and with single pointed tip, basal part with well visible lateral arm, tips of teeth orientated ventrally (Figs. 4a, b and 6e); labrum very large and long with massive basal part, anterior part of labrum strongly curved downward appearing to represent a third, middle mouthhook (Figs. 4a, b and 6e); intermediate sclerite short, partly hidden behind parastomal bar in lateral view but clearly shifted toward anterior end of body under base of labrum (Fig. 6e, f); parastomal bars short and broad (Fig. 6e, f); vertical plate wide, about three times wider than width of ventral cornua; dorsal cornua longer than ventral cornua, but both cornua of similar width (Fig. 6e); dorsal bridge present. Thoracic segments: anterior spinose band on t1 broad, with spines arranged in 5-6 rows dorsally and 9-11 rows ventrally, spines very large more conical than in Chrysomya bezziana, elongated and slightly curved, size of spines decreasing gradually towards the posterior end of body (Fig. 4a, b); anterior spinose bands of $\mathrm{t} 2$ and $\mathrm{t} 3$ with homogeneous, strongly sclerotised, elongated spines. Abdominal segments: anterior spinose bands complete on a1-a5, on a6 band narrowly interrupted dorsally, on a7 the band incomplete, restricted to ventral surface and few spines on dorso-lateral surfaces, each anterior spinose band ventrally with a transverse lenticular gap without spines (Figs. 5b and 7c); posterior spinose band on a1a6 band present as a single row of ventral spines with few additional spines ventro-laterally, band on a7 complete with a single row of spines on lateral surfaces and with 2-3 rows ventrally and dorsally; lateral creeping welts with strong spines directed posteriorly, only the most posterior lateral creeping welt without spines. Anal division: Anal pads rounded, small and slightly protruding (Fig. 5e), anal tuft with several spines dorsally, readily apparent in light microscope; hair-like spines around spiracular cavity present but sparse (Fig. 5d); posterior spiracles hidden in spiracular cavity (Fig. 5d); p1, p3 and p5 developed as large cones with a long sensillum on the extremity resembling a large sensillum coeloconicum (Fig. 5c, d), p7 with sensillum on small protuberance, p2, p4 and p6 developed as sensilla situated level with adjacent integument.

\section{Key to the first instar larva of obligatory traumatic wound myiasis agents of domestic animals and humans}

The following keys will serve to separate the first instar of the three known OTMAs from other calyptrates and reliably identify them to species:

1. Posterior spiracular cavity absent, spiracles exposed on a flat or slightly concave spiracular field (Figs. $1 \mathrm{~g}$ and $3 \mathrm{~d}$ )...2

Deep spiracular cavity present, posterior spiracles hidden (Fig. 5d)...4 

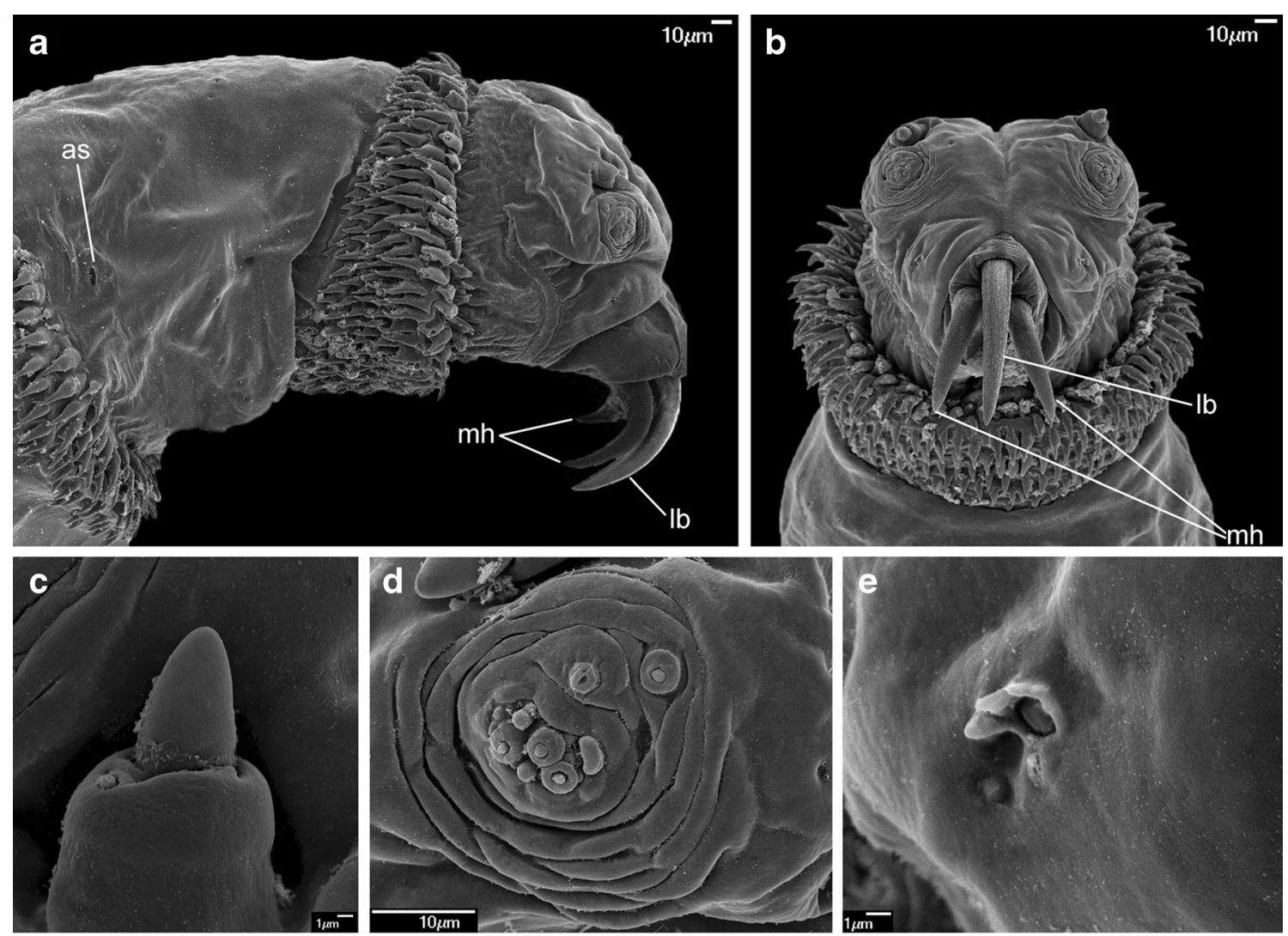
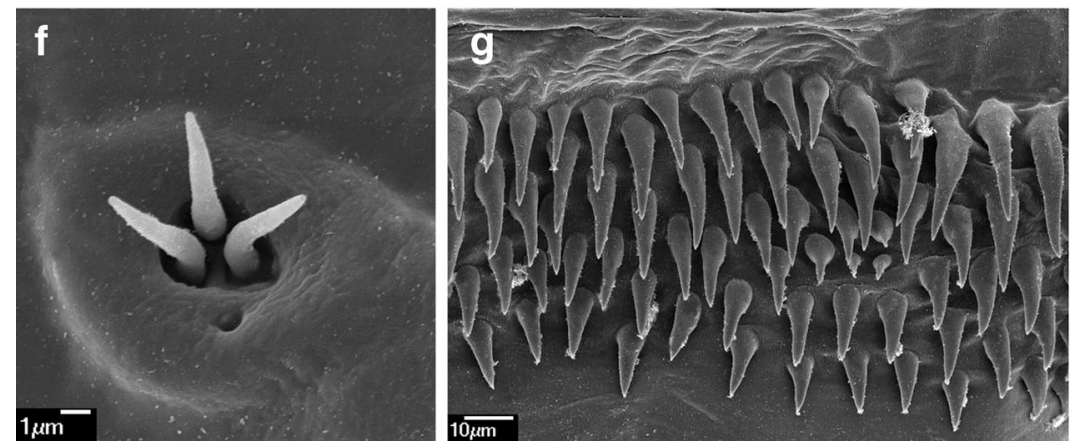

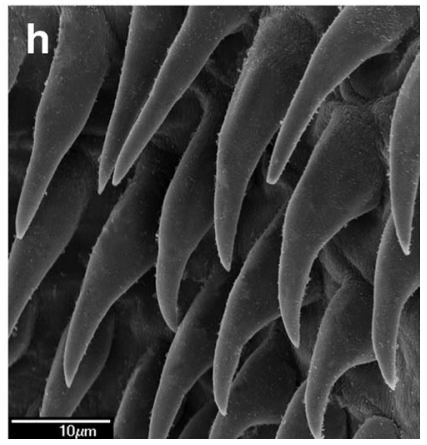

segment, spines. h Second abdominal segment, spines. Abbreviations: as anterior spiracle, $l b$ labrum, $m h$ mouthhooks lateral view. b Anterior end of body, ventral view. c Antennal complex. d Maxillary palpus. e Ventral organ. f Keilin's organ. g Third thoracic

2. Teeth of mouthhooks and cirri strong, large and curved (Figs. 1b, 2e and 6a, c); oral ridges terminate mediolaterally on pseudocephalon (Figs. 1a and 2a), spines of spinose bands relatively large and strongly sclerotised (Fig. 7a, b), hair-like spines around spiracular field absent (Figs. 1g and 3d), peristigmatic tufts with broad and short branches, cleft at most to centre of tuft (Figs. $1 \mathrm{~g}$ and $3 \mathrm{~d}) \ldots 3$

Teeth of mouthhooks and cirri distally slender and mostly straight (see Szpila et al. 2013, Fig. 3e), oral ridges terminate dorso-laterally on pseudocephalon (see Szpila et al. 2013, Fig. 3a, b), spines of spinose bands relatively small and weakly sclerotised (Fig. 7d), hair-like spines around spiracular field present, branches of peristigmatic tufts long and slender, cleft almost to base of tuft (see Szpila et al. 2013, Fig. 4d, e, h)...(other Calliphoridae)

3. Mouthhooks with apical teeth clearly differentiated in size with three to four teeth of each mouthhook larger than remaining teeth/cirri (Fig. 1b), basal part of labrum about $1.5 \times$ longer than narrow apical part (Fig. 6a), dorsal bridge present (Fig. 6b), posterior spinose band on segment a7 complete (Fig. 7a)...Chrysomya bezziana

Mouthhooks with apical teeth only slightly differentiated in size (Fig. 2e), basal part of labrum at least $3 \times$ longer than narrow apical part (Fig. 6c), dorsal bridge absent (Fig. 6d), posterior spinose band on segment a 7 incomplete (Fig. 7b) ... Cochliomyia hominivorax 

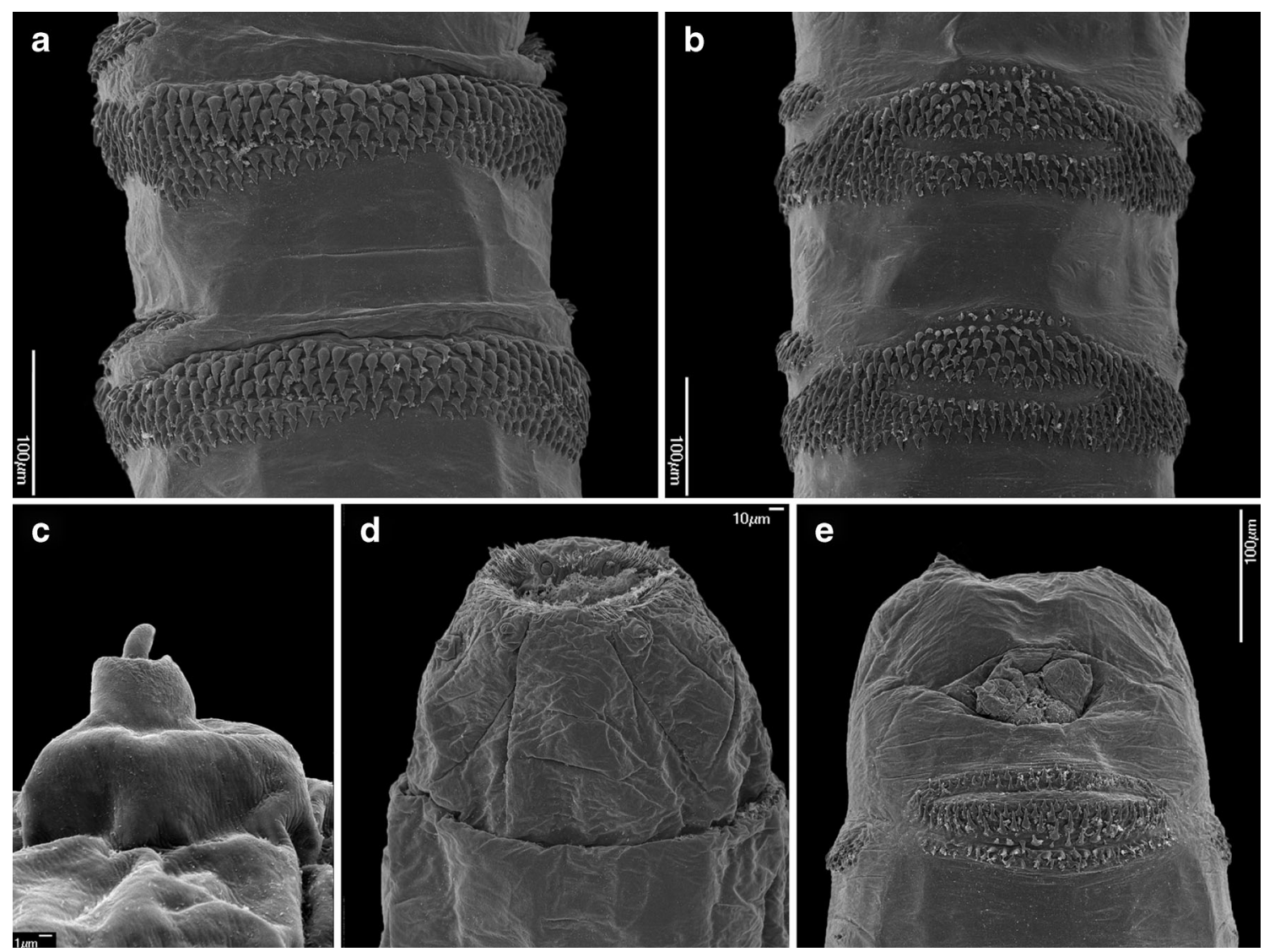

Fig. 5 First instar of Wohlfahrtia magnifica. a Third abdominal segment, dorsal view. b Third abdominal segment, ventral view. c Anal division, papilla p5. d Anal division, posterior end, dorsal view. e Anal division, posterior end, ventral view

4. Labrum of cephaloskeleton well developed, distinctly visible between the paired mouthhooks (Figs. 4a, b; 6e-f)...5

Labrum of cephaloskeleton vestigial, only the paired mouthhooks well visible...Sarcophaginae

5. Anterior part of labrum and mouthhooks abruptly and almost perpendicularly curved downward (Fig. 6e), spines of spinose bands large and strongly sclerotised (Fig. 7c), posterior spinose bands on a5-a6 incomplete, interrupted dorsally (Fig. 7c)...W. magnifica

Anterior part of labrum and mouthhooks gently and gradually curved downward (see Szpila and Villet 2011, Fig. 10j), spines of spinose bands small and weakly sclerotised, posterior spinose bands on a5-a6 complete...(other Paramacronychiinae)

\section{Discussion}

Verification of earlier descriptions

Existing data on L1 morphology of OTMA species are very uneven with regard to the quality of the illustrations and the accuracy of the descriptions. The first report of the L1 of
Chrysomya bezziana provided by Zumpt (1965) is only a vague description of the general appearance of larvae with a note about the serrated tips of the mouthhooks. More comprehensive documentation was published by Kitching (1976), but several misinterpretations of the distribution and composition of the spinose bands are obvious. Firstly, Kitching (1976) treated the anterior spinose band of $\mathrm{t} 1$ as an integral part of the pseudocephalon (head segment with a posterior ruff-like structure with five to six rows of irregularly aligned spines). An indirect consequence of this interpretation is the erroneous statement that thoracic and abdominal segments possess only a posterior spinose band. True posterior spinose bands on abdominal segments are interpreted as "one row of these smaller spines along the anterior margins of spine bands". However, the SEM micrograph of the ventral abdominal surface presented by Kitching (1976, Fig. 23) shows that the larval spinulation analysed by him was of the same type as that described in the present paper, with a broad anterior spinose band and a narrow incomplete posterior spinose band. Gan (1980) presented only a very short description of the cephaloskeleton, but it was supported by a very good line drawing. This figure of the cephaloskeleton is fully congruent with the cephaloskeleton of Chrysomya bezziana as presented here. Spradbery (2002), in a manual for diagnosis of screw- 


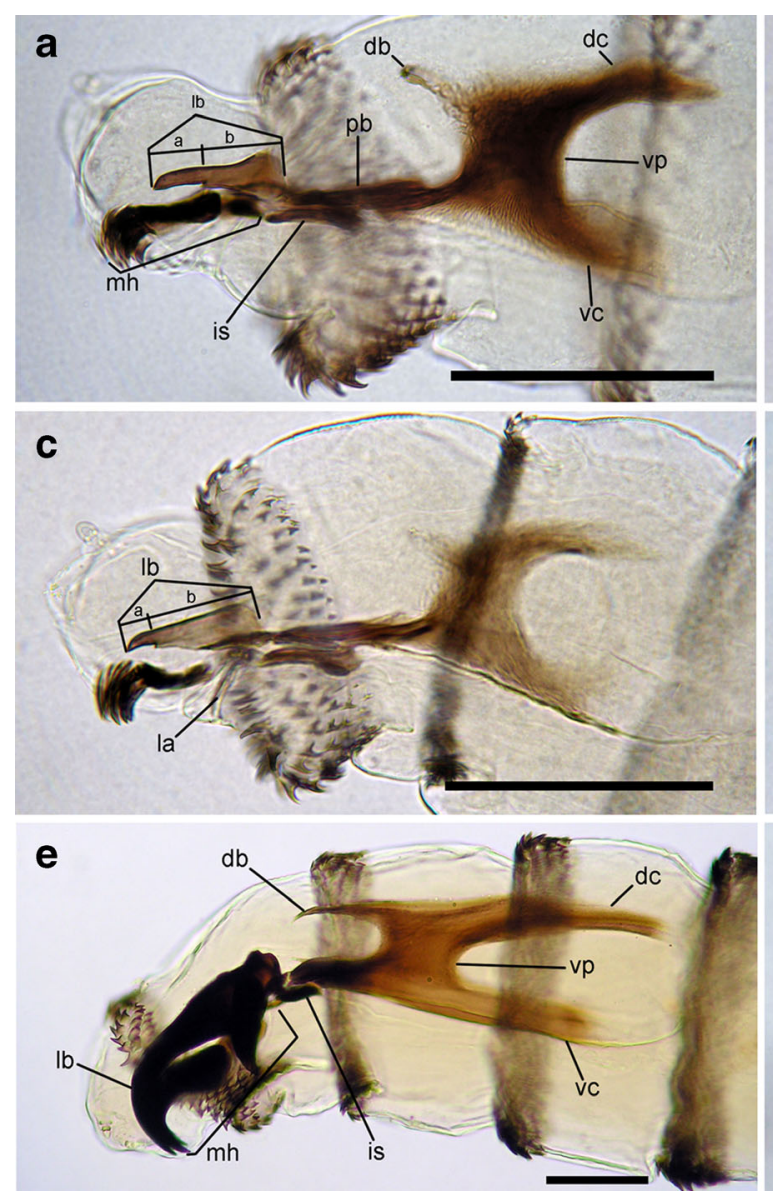

Fig. 6 Cephaloskeleton of OTMA. a Chrysomya bezziana, lateral view. b Chrysomya bezziana, ventral view. c Cochliomyia hominivorax, lateral view. d Cochliomyia hominivorax, ventral view. e Wohlfahrtia magnifica, lateral view. f Wohlfahrtia magnifica, ventral view. Scale bar $=0.1 \mathrm{~mm}$.

worm flies, provided only a superficial description of the L1 of Chrysomya bezziana without any details.

Documentation of the L1 morphology available for Cochliomyia hominivorax is generally much better, mostly thanks to Laake et al. (1936). These authors provided a detailed description of the cephaloskeleton and spinulation, line drawings of the cephaloskeleton and a habitus of the entire larva. All details of their documentation are congruent with the data presented here. Noteworthy is the contribution of Lopes (1983), with a figure of the anterior part of the cephaloskeleton of the L1 of Cochliomyia hominivorax. Interestingly, Lopes (1983) interpreted the apical teeth of the mouthhook (conspicuous series of spines on the margins of oral atrium) as structures separated from mouthhooks (maxilla). This kind of interpretation was common in previous descriptions of the $\mathrm{L} 1$ of blowflies (Szpila et al. 2008). However, the strongly sclerotised mouthhook of Cochliomyia hominivorax provides firm evidence (see Fig. 6c, d) that at least some of these exposed teeth are an integral part of the mouthhook. The next major contribution to larval morphology of Cochliomyia hominivorax was published by Leite and Guevara (1993) and was based mostly
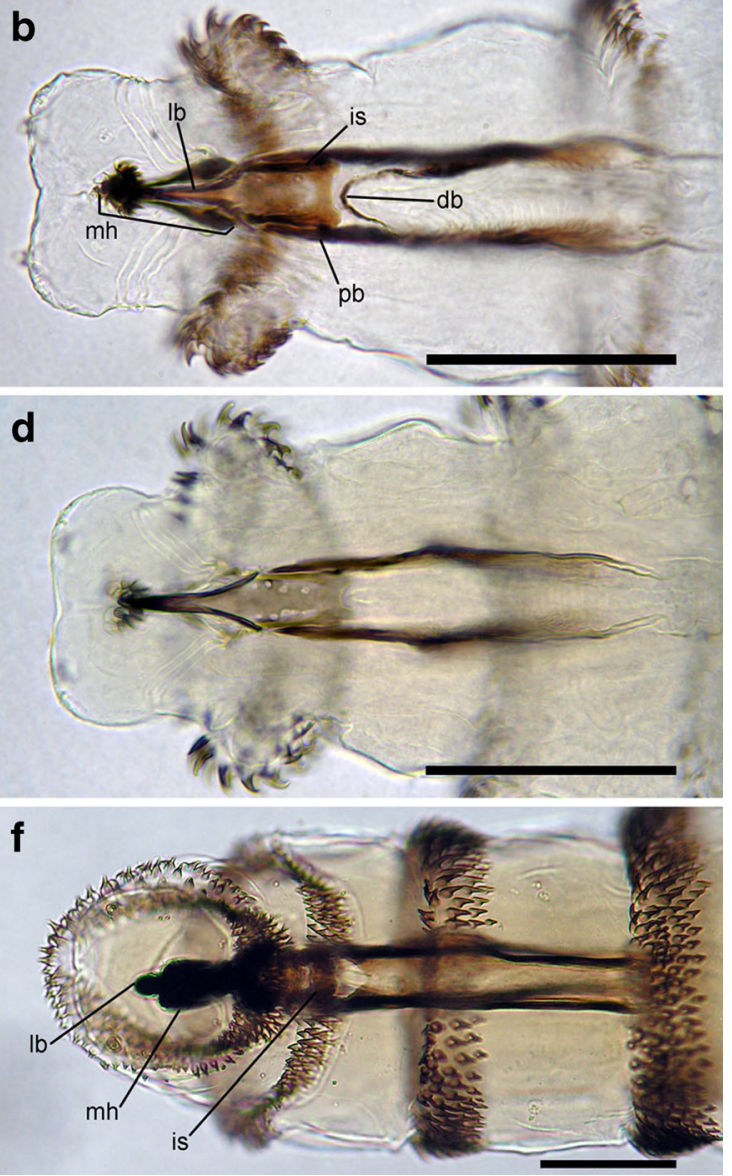

Abbreviations: $a$ length of apical part of labrum, $b$ length of basal part of labrum, $d b$ dorsal bridge, $d c$ dorsal cornua, is intermediate sclerite, la lateral arm, $l b$ labrum, $m h$ mouthhook, $p b$ parastomal bar, $v c$ ventral cornua, $v p$ vertical plate

on SEM micrographs. In comparison to the present data only one important difference was found: Leite and Guevara (1993) reported the presence of three peristigmatic tufts on each posterior spiracle, but SEM micrographs in their own publication (Leite and Guevara 1993, Figs. 11 and 12) and in the present paper (Fig. 3d) all show four peristigmatic tufts. A technical mistake is apparent in Fig. 10 of Leite and Guevara (1993) where the anal division is presented upside down and the anal opening $(\mathrm{k})$ is marked between the posterior spiracles instead of between the anal pads.

Valentyuk (1971) presented details of the L1 of W. magnifica in the context of an identification key to larvae of Whlfahrtia of Crimea and the north coast of the Black Sea. The data provided are sparse but refer to characters of significant taxonomic importance: the shape of mouthhooks and labrum; and the size, sclerotisation and distribution of spines on the segments a6-a7. One difference noted between the data of Valentyuk (1971) and those presented here concerns the posterior spinose band on a7. In our material, the posterior spinose band encircles all of a7 (in the form of a single row of spines both laterally and dorsally) whereas Valentyuk (1971) 
Fig. 7 Habitus. a Chrysomya bezziana. b Cochliomyia hominivorax. c Wohlfahrtia magnifica. d Lucilia cuprina. Abbreviations: al-a7 abdominal segments 1-7, ad anal division, $p c$ pseudocephalon, $t 1-t 3$ thoracic segments $1-3$. Scale bar $=0.1 \mathrm{~mm}$
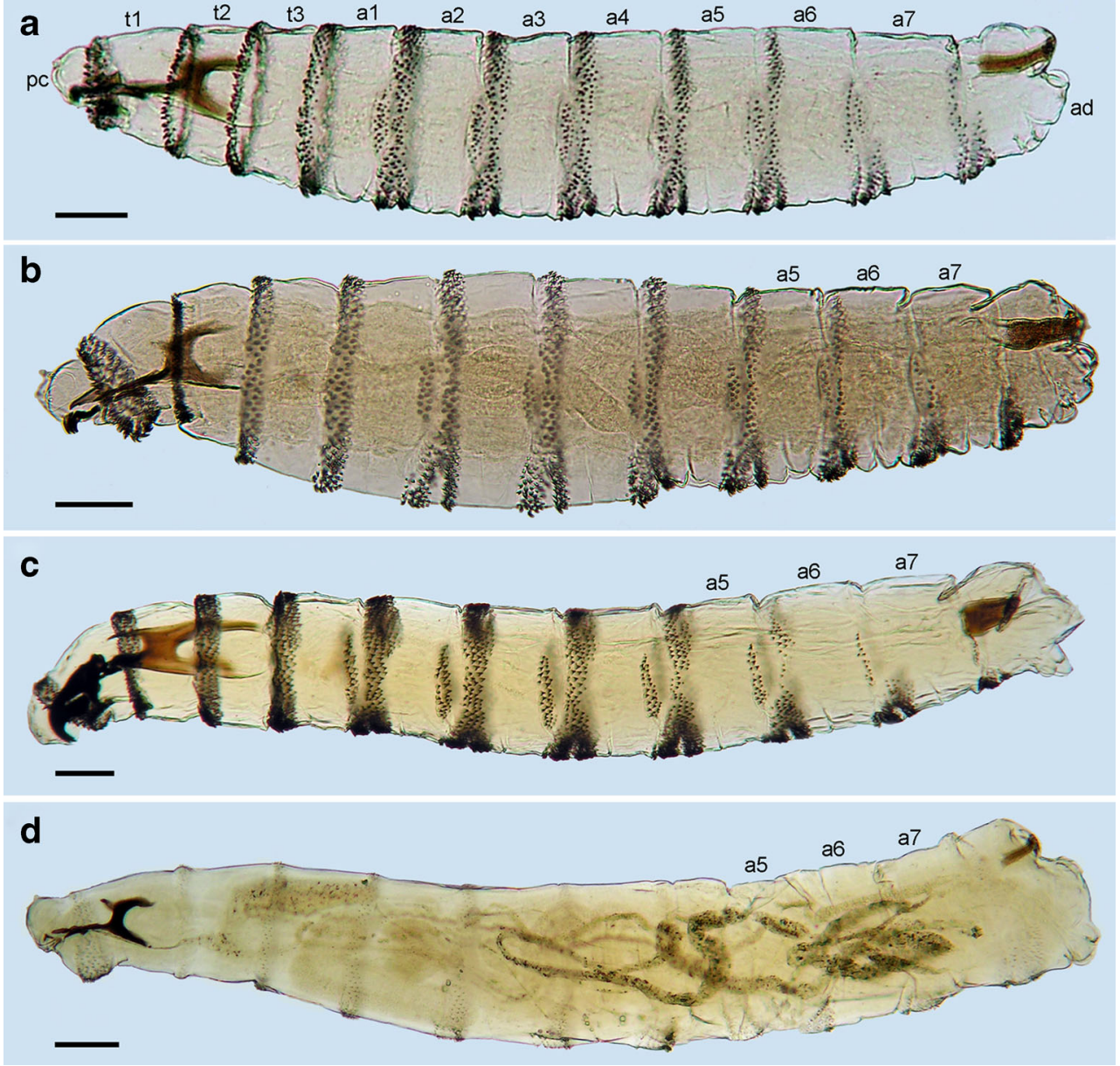

reported spines to be entirely absent on the dorsal surface of a6-a7 and on the anal division. A detailed study of the L1 of W. magnifica provided by Schumann et al. (1976) is largely congruent with the present data regarding the shape of the cephaloskeleton and details of spinulation. One discrepancy concerns the degree of development of the anterior spinose band on the anal division. Schumann et al. (1976) described it as incomplete, similarly to Valentyuk (1971). Lehrer and Fromunda (1986) also provided valuable documentation of the L1 of W. magnifica. Their contribution is mostly restricted to characters of the cephaloskeleton and is fully congruent with the present data. The first extensive study of the larval morphology of W. magnifica was published by Ruiz-Martinez et al. $(1989,1990)$. Unfortunately, these publications contain a few significant misinterpretations: (1) the labrum is treated as a third mouthhook "identical to the lateral ones, morphologically and ultrastructurally"; (2) the intermediate sclerite is interpreted as a "parastomal sclerite of interinstar I-II"; (3) the dorsal bridge (as "dorsal arc") of the cephaloskeleton is absent; and (4) the spines of the anterior spinose band on $\mathrm{t} 1$ are interpreted as "modified buccal spines". An unpaired labrum situated between the paired mouthhooks is typical for the L1 of most Oestroidea (e.g. Grunin 1955; Ferrar 1987; Szpila
2010) except for larvae of Oestrinae (Grunin 1957), Sarcophaginae (Lopes 1983) and Rhinophoridae (Bedding 1973; Pape and Arnaud 2001). Presence of a large hook-like labrum seems to be characteristic for species of Paramacronychiinae (e.g. Thompson 1921; Valentyuk 1971; Lopes 1983; Verves 1988) and should not be treated (even in a functional approach) as a "third mouthhook". The interpretation of the presence of a fully formed dorsal bridge is still rather open-it is possible that this structure is weakly sclerotised in early first instar larvae and that it may be interpreted as the lack of a fully developed dorsal bridge. The presence of "modified buccal spines" as described by Ruiz-Martinez et al. (1989) appears to be a misinterpretation. No "buccal spines" are reported or documented on the SEM micrographs of the L1 of W. magnifica by Ruiz-Martinez et al. (1990) in a paper published one year later, nor on the SEM images in the present paper. The description of Ruiz-Martinez et al. $(1989,1990)$ of the L1 spinulation is superficial and with the only taxonomically valuable information that the spines are strongly sclerotised. The mention by Ruiz-Martinez et al. (1989) of the presence of a "triangular sclerotised plate between the dorsal and ventral cornua (Fig. 1a, h)" as a character of significant taxonomic importance is of interest. This 
structure was not present in any larvae in our material. RuizMartinez et al. (1990) also stated that the "mouthhooks are always projected [...] because their dimension limit the retraction into cephalic segment". This is an apparent misinterpretation-specimens of $W$. magnifica with entirely retracted cephaloskeletons are presented in the present publication (Fig. 6c). The large and elongated labrum may be fully retracted also in the first instar of Sarcophila latifrons (Fallén, 1817) as well as in some (probably most) species of Miltogramminae (Szpila 2010).

\section{Convergent morphology in OTMA species}

Species of OTMA belong to quite distantly related taxonomic units. Chrysomya bezziana and Cochliomyia hominivorax are classified in the same subfamily Chrysomyinae, but are situated on relatively distant branches of the phylogenetic tree of Calliphoridae (McDonagh and Stevens 2011). Wohlfahrtia magnifica represents a separate family, Sarcophagidae. Morphological and molecular data strongly support an independent origin of obligatory parasitism for each of the OTMA species (Hall et al. 2009; McDonagh and Stevens 2011). Consequently, the distinct morphological similarities can only be explained as convergent evolution and may be suspected to be homoplasic adaptations for feeding in living vertebrate tissues. Shared character states of the first instar of OTMA species not found in closely related necrophages and facultative parasites are the following: (1) strongly sclerotised anterior structural elements of the cephaloskeleton; (2) teeth of mouthhooks and cirri apically strongly curved, hooklike; (3) spinose bands on t1-t3 and a1-a7 with strongly sclerotised, enlarged spines; (4) reduction of spinose bands on segments a6, a7 and anal division. The L1 of Chrysomya bezziana and Cochliomyia hominivorax, being more closely related to each other than to $W$. magnifica, possess further convergent specific character states in comparison to necrophagous and facultative parasitic species, i.e. (1) shortening of oral ridges, which terminate medio-laterally on the pseudocephalon; (2) absence of hairlike spines around the spiracular field on the anal division; and (3) peristigmatic tufts with broad and sparsely dichotomous branches.

Acknowledgements We are very grateful to Dong Zhang (Beijing Forestry University) for translating the Chinese text of professor Gan's description of the larvae of Chrysomya bezziana. The present work was supported financially by the Polish National Science Centre (grant no. 2012/07/B/NZ8/00158).

Open Access This article is distributed under the terms of the Creative Commons Attribution License which permits any use, distribution, and reproduction in any medium, provided the original author(s) and the source are credited.

\section{References}

Adams ZJO, Hall MJR (2003) Methods used for the killing and preservation of blowfly larvae, and their effect on post-mortem larval length. Forensic Sci Int 138:50-61

Cielecka D, Salamatin R, Garbacewicz A (2009) Usage of the Hoyer's medium for diagnostics and morphological studies of some parasites. Wiad Parazytol 50:265-270 [In Polish with English abstract]

Courtney GW, Sinclair BJ, Meier R (2000) Morphology and terminology of Diptera larvae. In: Papp L, Darvas B (eds) Contributions to a Manual of Palaearctic Diptera (with special reference to flies of economic importance). Science Herald Press, Budapest, pp 85-161

Erzinçlioğlu YZ (1987) The larvae of some blowflies of medical and veterinary importance. Med Vet Entomol 1:121-125

Ferrar P (1987) A guide to the breeding habits and immature stages of Diptera Cyclorrhapha. Entomonograph 8:1-907

Florez E, Wolff M (2009) Descripción y clave de los estadios inmaduros de las principales especies de Calliphoridae de importancia forense en Colombia. Neotropical Entomol 38:418-429

Gan YX (1980) On the larvae of the Chinese species of the subfamily Chrysomyinae (Dipt. Calliphoridae). Zool Res 1:179-196

Grunin KJ (1955) Zheludochnye ovody (Gastrophilidae). Fauna SSSR, N.S. $17: 1-96$

Grunin KJ (1957) Nosoglotochnye ovody (Oestridae). Fauna SSSR, N.S. 19:1-147

Grzywacz A, Pape T, Szpila K (2012) Larval morphology of the Lesser House Fly Fannia canicularis (Diptera: Fanniidae). Med Vet Entomol 26:70-82

Hall MJR (2008) New World screwworm (Cochliomyia hominivorax) and Old World screwworm (Chrysomya bezziana). Chapter 2.1.10. In: OIE Biological Standards Commission (ed) Manual of diagnostic tests and vaccines for terrestrial animals (mammals, birds and bees), vol 1, Sixthth edn. OiE, World Organisation for Animal Health, Paris, France, pp 265-275

Hall MJR, Farkas R (2000) Traumatic myiasis of humans and animals. Chapter 1.18. In: Papp L, Darvas B (eds) Contributions to a Manual of Palaearctic Diptera (with special reference to flies of economic importance). Science Herald, Budapest, pp 751-768

Hall MJR, Wall R (1995) Myiasis of humans and domestic animals. Adv Parasitol 35:257-334

Hall MJR, Adams ZJO, Wyatt NP, Testa JM, Edge W, Nikolausz M, Farkas R, Ready PD (2009) Morphological and mitochondrial DNA characters for identification and phylogenetic analysis of the myiasis causing fleshfly Wohlfahrtia magnifica and its relatives, with a description of Wohlfahrtia monegrosensis sp. n. Wyatt and Hall. Med Vet Entomol 23(Suppl 1):59-71

Kitching RL (1976) The immature stages of the Old-World screw-worm fly, Chrysomya bezziana Villeneuve, with comparative notes on other Australasian species of Chrysomya (Diptera, Calliphoridae). Bull Entomol Res 66:195-203

Klong-klaew T, Sukontason K, Sribanditmongkol P, Moophayak K, Sanit S, Sukontason KL (2012) Observations on morphology of immature Lucilia porphyrina (Diptera: Calliphoridae), a fly species of forensic importance. Parasitol Res 111:1965-1975

Knipling EF (1939) A key for blowfly larvae concerned in wound and cutaneous myiasis. Ann Entomol Soc Am 32:376-383

Laake EW, Cushing EC, Parish HE (1936) Biology of the primary screw worm fly, Cochliomyia americana, and a comparison of its stages with those of $C$. macellaria. Tech Bull USDA 50:1-24

Lehrer AZ, Fromunda V (1986) Le dévelopment larvaire du diptère myiasigène Wohlfahrtia magnifica (Schiner) (Diptera, Sarcophagidae). Bull Ann Soc R Entomol 122:129-136

Leite ACR, Guevara JDE (1993) Scanning electron microscopy of the larval instars of Cochliomyia hominivorax. Med Vet Entomol 7: 263-270 
Lindquist DA, Abusowa M, Hall MJR (1992) The New World screwworm fly in Libya: a review of its introduction and eradication. Med Vet Entomol 6:2-8

Lopes HS (1983) The importance of the mandible and clypeal arch of the first instar larvae in the classification of the Sarcophagidae (Diptera). Rev Bras Entomol 26:293-326

McDonagh LM, Stevens JR (2011) The molecular systematics of blowflies and screwworm flies (Diptera: Calliphoridae) using $28 \mathrm{~S} r R N A$, $C O X 1$ and $E F-1 \alpha$ : insight into evolution of dipteran parasitism. Parasitology 138:1760-1777

Pape T, Arnaud PH Jr (2001) Bezzimyia - a genus of New World Rhinophoridae (Insecta, Diptera). Zool Scr 30:257-297

Ruiz-Martinez I, Soler-Cruz MD, Benitez-Rodriguez R, Perez-Jimenez JM, Diaz-Lopez M (1989) Postembryonic development of Wohlfahrtia magnifica (Schiner, 1862) (Diptera: Sarcophagidae). J Parasitol 75:531-539

Ruiz-Martinez I, Soler-Cruz MD, Benitez-Rodriguez R, Perez-Jimenez JM, Adalid-Fuentes C, Diaz-Lopez M (1990) Scanning electron microscope study of Wohlfahrtia magnifica (Schiner, 1862) (Diptera: Sarcophagidae). I. Structures with parasitic and possible taxonomic meaning. Scanning Microsc 4:103-109

Sanit S, Sukontason KL, Sribanditmongkol P, Klong-klaew T, Samerjai C, Sontigun N, Limsopatham K, Sukontason K (2012) Surface ultrastructure of larva and puparia of blow fly Hypopygiopsis tumrasvini Kurahashi (Diptera: Calliphoridae). Parasitol Res 111: 2235-2240

Schumann H, Ribbeck R, Beulig W (1976) Wohlfahrtia magnifica (Schiner 1862) (Diptera: Sarcophagidae) als Ursache einer vaginalen Myiasis bei domestizierten zweihöckrigen in der Mongolischen Volksrepublik. Arch Expert Vet Med 30:220232

Semelbauer M, Kozánek M (2012) Morphology of preimaginal stages of Lauxania and Calliopum (Diptera: Lauxaniidae). Zootaxa 3346:1-28

Sotiraki S, Farkas R, Hall MJR (2010) Fleshflies in the flesh: epidemiology, population genetics and control of outbreaks of traumatic myiasis in the Mediterranean Basin. Vet Parasitol 174:12-18

Spradbery JP (1994) Screwworm fly: a tale of two species. Agric Zool Rev 6:1-62
Spradbery JP (2002) A manual for the diagnosis of screw-worm fly. Department of Agriculture, Fisherines \& Forestry - Australia, Canberra

Sutherst RW, Spradbery JP, Maywald GF (1989) The potential geographical distribution of the Old World screw-worm fly, Chrysomya bezziana. Med Vet Entomol 3:273-280

Szpila K (2010) The first instar of European Miltogramminae (Diptera, Sarcophagidae). Wydawnictwo Naukowe UMK, Toruń

Szpila K, Pape T, Rusinek A (2008) Morphology of the first instar larva of Calliphora vicina, Phormia regina and Lucilia illustris (Diptera, Calliphoridae). Med Vet Entomol 22:16-25

Szpila K, Villet M (2011) Morphology and identification of first instar larvae of African blowflies (Diptera: Calliphoridae) commonly of forensic importance. J Med Entomol 48:738-752

Szpila K, Hall MJR, Sukontason K, Tantawi T (2013) Morphology and identification of the first instar larvae of European and Mediterranean blowflies of forensic importance. Part I: Chrysomyinae. Med Vet Entomol 27:181-193

Thompson WR (1921) Recherches sur les diptères parasites. ILes larves des Sarcophagidae. Bull Biol Fr Belg 54:313463

Valentyuk EI (1971) The first stage larvae of species of genus Wohlfahrtia B.B. (Diptera: Sarcophagidae) from Crimea and Northern Black Sea area. Vestnik Zool 3:78-81

Velasquez Y, Ivorra T, Grzywacz A, Martínez-Sánchez A, Magaña C, García-Rojo A, Rojo S (2013) Larval morphology, development and forensic importance of Synthesiomyia nudiseta (Diptera: Muscidae) in Europe: a rare species or just overlooked? Bull Entomol Res 103: $98-110$

Verves YuG (1988) The importance of construction of the pharyngeal structures of the first stage larvae for the taxonomy of Palaearctic Sarcophagidae (Diptera). In: Dolin VG, Zerova MD, Kononova SV, Blinstein SJ (eds) Ecology and taxonomy of the Ukrainian insects. Kiev, pp 99-107 (in Russian)

Zumpt F (1965) Myiasis in man and animals in the Old World. A textbook for physicians, veterinarians and zoologists. Butterworth's, London 